\title{
Impact of ecosystem respiration on carbon balance in a semi-evergreen forest of Northeast India
}

\author{
Dipankar Sarma ${ }^{1}$, Kushal Kumar Baruah ${ }^{1, *}$, Supriyo Chakraborty ${ }^{2}$, \\ Anand Karipot ${ }^{3}$ and Rulee Baruah ${ }^{4}$ \\ ${ }^{1}$ Department of Environmental Science, Tezpur University, Tezpur 784 028, India \\ ${ }^{2}$ Indian Institute of Tropical Meteorology, Pune 411 008, India \\ ${ }^{3}$ Savitribai Phule Pune University, Pune 411007 , India \\ ${ }^{4}$ Prince of Wales Institute of Engineering and Technology, Jorhat 785 001, India
}

We have estimated in this study the annual net ecosystem productivity (NEP) of Kaziranga National Park by using real-time eddy covariance data. We partitioned the net $\mathrm{CO}_{2}$ flux into gross primary productivity and ecosystem respiration $\left(R_{e}\right)$ using standardized method. Estimated annual NEP of the ecosystem $92.93 \pm 1.7 \mathrm{~g} \mathrm{C} \mathrm{m}^{-2}$ year $^{-1}$ indicated that the forest is a moderate sink of $\mathrm{CO}_{2}$ and is reported for the first time from a forest of Northeast India.

Keywords: Eddy covariance, gross primary productivity, net ecosystem productivity.

THE concentration of carbon dioxide $\left(\mathrm{CO}_{2}\right)$ in the atmosphere is increasing from the last several decades which has affected the radiative characteristics of the atmosphere. The exchange of $\mathrm{CO}_{2}$ between forest and atmosphere is believed to have a profound impact on the regulation of atmospheric $\mathrm{CO}_{2}$ concentration ${ }^{1}$. The role of forest in the regulation of the global carbon cycle is important $^{2}$. Gross primary productivity (GPP) of terrestrial ecosystem is considered as the largest global $\mathrm{CO}_{2}$ flux and is estimated as $123 \pm 8 \mathrm{Pg} \mathrm{C}$ per year ${ }^{3}$. GPP of a forest is primarily a function of photosynthetically active radiation (PAR) and leaf area index (LAI) of forest canopy ${ }^{4}$. Ecosystem respiration of forest is reported to be modulated by variation of soil and air temperature ${ }^{5}$. Eddy covariance (EC) is an efficient method for high frequency measurement of trace gas fluxes between atmosphere and biosphere ${ }^{1}$. It is essential to partition the net $\mathrm{CO}_{2}$ flux of any ecosystem into its components for mechanistic interpretation of the processes in the ecosystems ${ }^{6}$.

Ecosystem respiration is the major determinant of net ecosystem carbon exchange ${ }^{6}$. Soil respiration (plant root respiration and microbial respiration) contributes about $65 \%$ to total ecosystem respiration ${ }^{5}$. The rate of increase

*For correspondence. (e-mail: kkbaruah14@gmail.com) of soil organic matter (SOM) decomposition may change an ecosystem from sink to source ${ }^{7}$. Decomposition of SOM in forest ecosystem may rise along with increase of microbial activity due to an increase in temperature, moisture and litter input ${ }^{8}$.

The Kaziranga National Park (KNP) falls within the Asian monsoon zone which receives large amount of rainfall during the pre-monsoon, monsoon and the transition phase of summer to autumn in October. As a result, the park encounters frequent flood events ${ }^{9}$. We have earlier reported monthly variations of turbulent $\mathrm{CO}_{2}$ flux ${ }^{10}$ from this site and GPP was estimated using a calibrated model $^{11}$. There are only a few tropical forest sites in the Indian subcontinent from which internal carbon dynamics has been reported ${ }^{12}$. In this study, we have made an effort to partition net $\mathrm{CO}_{2}$ flux into its component fluxes from the semi-evergreen forest of KNP located in this unique climatic zone.

\section{Materials and methods}

\section{Site description}

The forest site under study $\left(26^{\circ} 34^{\prime} 48^{\prime \prime} \mathrm{N}, 93^{\circ} 6^{\prime} 28^{\prime \prime} \mathrm{E}\right)$ is inside KNP which is located on the border of the Eastern Himalaya partly in Nagaon and Golaghat districts of Assam, India. The forest is considered as a biodiversity hotspot which hosts a variety of plant and animal species. The experimental site inside the forest is a part of 'Metflux India' project carried across the Indian subcontinent by the Indian Institute of Tropical Meteorology (IITM), Pune. The EC set-up and other meteorological sensors installed in the site are being monitored and maintained by the Tezpur Central University which is about $60 \mathrm{~km}$ away from the experimental site. Figure 1 shows the location and photograph of the flux tower. The average canopy height around the tower is $20 \mathrm{~m}$. Dominant plant species around the flux tower are listed in Table 1. 
Table 1. Dominant plant species around the tower

\begin{tabular}{lll}
\hline Scientific name & Family & Canopy/height \\
\hline Gmelina arborea Roxb. & Lamiaceae & Medium \\
Mallotus repandus (Willd.) Müll. Arg. & Euphorbiaceae & High \\
Tetrameles nudiflora R. Br. & Tetramelaceae & High \\
Psidium guajava L. & Myrtaceae & Small \\
Dalbergia sissoo DC. & Papilionaceae & High \\
Lagerstroemia speciosa (L.) Pers. & Lythraceae & High \\
Derris indica (Lam.) Bennet & Papilionaceae & High \\
Syzygium cumini (L.) Skeels & Myrtaceae & High \\
Dysoxylum mollissimum Blume & Meliaceae & High \\
Albizia lebbeck (L.) Benth. & Mimosaceae & Moderate \\
Bridelia retusa (L.) A.Juss. & Phyllanthaceae & Moderate \\
Erythrina indica Lam. & Papilionaceae & Moderate \\
Pennisetum purpureum Schumach. & Poaceae & Low \\
Chrysopogon zizanioides (L.) Roberty & Poaceae & Low \\
\hline
\end{tabular}
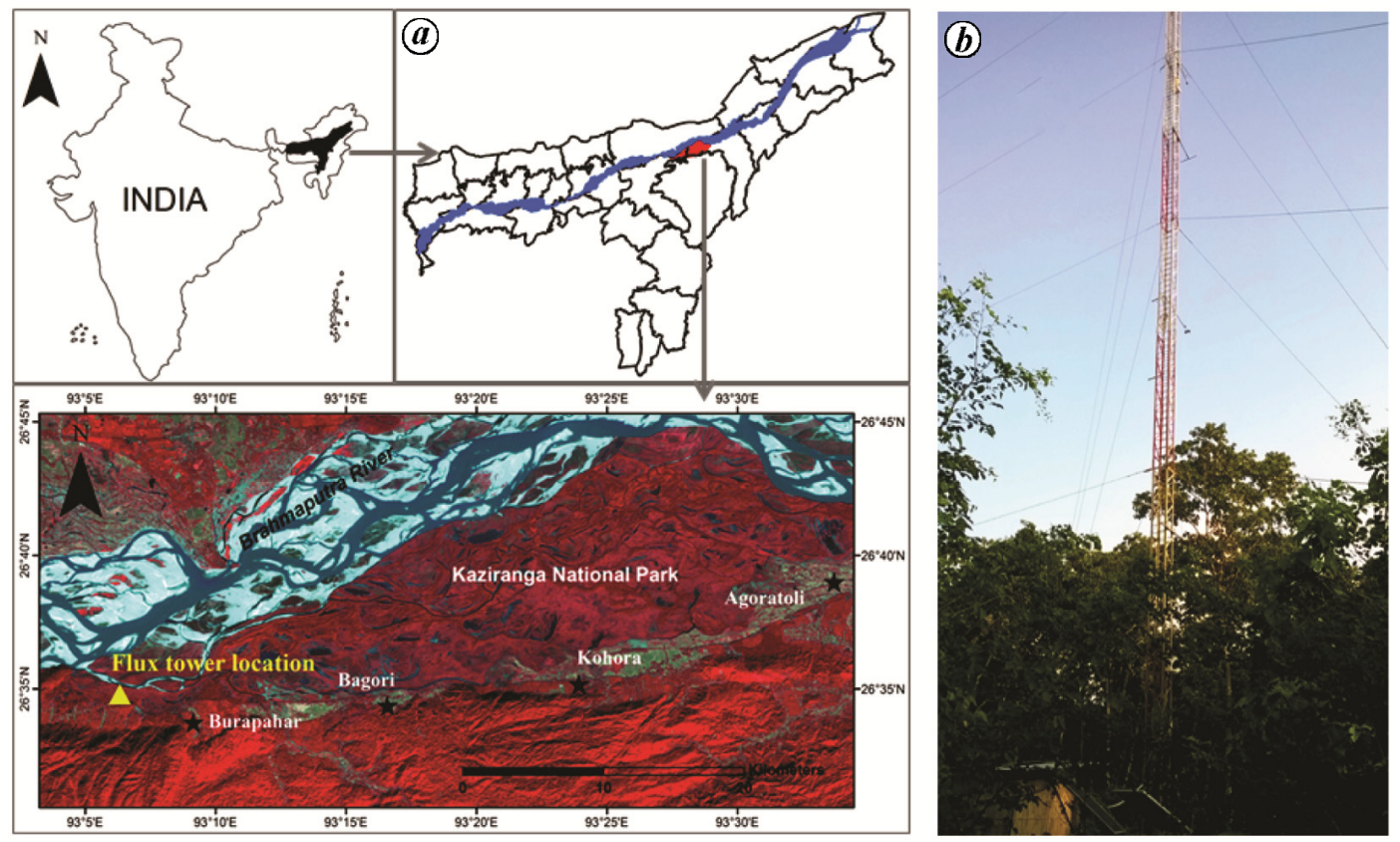

Figure 1. $\boldsymbol{a}$, The location of the experimental site in map. $\boldsymbol{b}$, Photograph of the tower.

\section{EC system}

$\mathrm{CO}_{2}$ flux above the canopy (at $37 \mathrm{~m}$ height) was measured with the help of EC system which includes a sonic anemometer (Wind Master Pro, Gill Instruments, UK) and a $\mathrm{CO}_{2}-\mathrm{H}_{2} \mathrm{O}$ closed path analyser (LI-7200, LI-COR, USA) ${ }^{10}$.

\section{Measurement of meteorological and soil parameters}

The soil temperature was measured by using soil temperature sensor (model: Therm-SS, ICT International, Australia) at $5 \mathrm{~cm}$ depth. Temperature of air and rainfall was measured using a multicomponent weather sensor
(WXT520, Vaisala Oyj, Finland) at the height of $37 \mathrm{~m}$ on the tower. Radiation components were measured at $24 \mathrm{~m}$ height using a four-component net radiometer (NR01, Hukseflux, The Netherlands). The PAR sensor (SQ-100 and 300 series, Apogee Instruments, USA) was also installed at the height of $24 \mathrm{~m}$ on the tower for measurement of incoming PAR. Data from all the above slow sensors were recorded together at $30 \mathrm{~min}$ average in a data logger (CR3000, Campbell Scientific, USA).

\section{Calculation of net ecosystem exchange of $\mathrm{CO}_{2}$}

Net ecosystem exchange (NEE) was calculated using the flux estimated by EC method $\left(F_{\mathrm{e}}\right)$ and storage flux $\left(S_{\mathrm{t}}\right)$ 
$\mathrm{NEE}=F_{\mathrm{e}}+S_{t}$

$F_{\text {e }}$ was calculated with the help of eddy-pro (6.2.0, LI-COR, USA) software and by following spike removal and filtering methods applied in our previous analysis ${ }^{10}$.

$\mathrm{CO}_{2}$ storage was estimated using the half hourly changes in $\mathrm{CO}_{2}$ concentration at $37 \mathrm{~m}$. Only one point concentration was used for storage flux calculation because of unavailability of vertical profile data during the period of study.

$$
S_{t}=\frac{P}{R T} \frac{\partial c(h)}{\partial t} h
$$

where $P$ is the atmospheric pressure, $T$ the temperature of air, $R$ the molar gas constant, $c$ the concentration of $\mathrm{CO}_{2}$ and $h$ is the height where concentration of $\mathrm{CO}_{2}$ is measured.

\section{Partitioning of NEE}

NEE was partitioned using the online tool of Max Planck Institute for Biogeochemistry (https://www.bgcjena.mpg.de/REddyproc/brew/REddyproc.rhtml) in which we selected day time-based algorithm ${ }^{13}$.

In the day time based approach of the partitioning tool, NEE was modelled using the rectangular hyperbolic light response function ${ }^{14}$

$$
\mathrm{NEE}=\frac{x y R}{x R+y}+r_{e},
$$

where $x$ indicates light utilization efficiency of canopy $\left(\mu \mathrm{mol} \mathrm{C} \mathrm{J}^{-1}\right), y$ denotes maximum $\mathrm{CO}_{2}$ uptake rate of

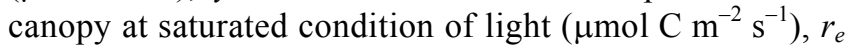
denotes total ecosystem respiration $\left(\mu \mathrm{mol} \mathrm{C} \mathrm{m}^{-2} \mathrm{~s}^{-1}\right)$ and $R$ indicates global solar radiation $\left(\mathrm{W} \mathrm{m}^{-2}\right)$. In the algorithm of the tool $r$ is replaced by respiration model according to Lloyd and Taylor ${ }^{15}$.

$$
\mathrm{NEE}=\frac{x y R}{x R+y}+r \exp \left(E_{0}\left(\frac{1}{T_{r f}-T_{0}}-\frac{1}{T_{a}-T_{0}}\right)\right),
$$

$T_{0}$ and $T_{\text {rf }}$ were fixed at $-46.02^{\circ} \mathrm{C}$ and $15^{\circ} \mathrm{C}$ respectively, similar to night time-based approach ${ }^{16}$. Night-time data $\left(R<4 \mathrm{Wm}^{-2}\right)$ was used for estimation of $E_{0}$ (activation energy parameter), after that $E_{0}$ was fixed and $r, x$ and $y$ were estimated using day-time data.

At high vapour pressure deficit (VPD), $y$ in the above equation was modified by an exponential decreasing function following Korner $^{17}$ to avoid limitation of VPD on GPP

$$
\begin{aligned}
& y=y_{0} \exp \left(-k\left(\mathrm{VPD}-\mathrm{VPD}_{0}\right)\right), \mathrm{VPD}>\mathrm{VPD}_{0}, \\
& y=y_{0}, \mathrm{VPD}<\mathrm{VPD}_{0} .
\end{aligned}
$$

For estimation of the parameter $k$, data window of each 4 day was used which quantifies maximum carbon uptake to VPD, $\mathrm{VPD}_{0}$ threshold was fixed at $10 \mathrm{hPa}$ following Korner $^{17}$.

\section{Analysis of soil organic carbon}

Soil samples were collected using an iron core from two depths $(0-15 \mathrm{~cm}$ and $15-30 \mathrm{~cm})$ and from four different sites during four seasons of the year: (i) winter (December, January and February), (ii) pre-monsoon (March, April and May), (iii) monsoon (June, July, August and September) and (iv) post-monsoon (October and November). The soil organic carbon (SOC) content of the samples was determined using TOC analyzer (Multi NC 2100S, Analytic Zena, Germany).

\section{Results and discussion}

Diurnal variation of soil temperature (monthly mean) is depicted in Figure $2 a$. Highest average soil temperature of $30.29^{\circ} \mathrm{C}$ was recorded in August 2016 which decreased to $14.37^{\circ} \mathrm{C}$ in January 2017 . Variation of soil and air temperature closely followed each other. Diurnal variation (monthly average) of incoming short wave radiation is shown in Figure $2 b$. Incoming radiation attained a peak of $754.225 \mathrm{~W} \mathrm{~m}^{-2}$ in August 2016 during noon hours. Annual total rainfall received by the site (Figure $2 c$ ) during the period of study was $1884 \mathrm{~mm}$. LAI of the forest canopy increased from February 2016 and attained a peak in the first half of June (3.25) and decreased slowly thereafter up to January 2017. Monthly average of day-time VPD in the study area during monsoon season is presented in Figure $2 d$. Out of the four monsoon months (June, July, August and September), the highest average VPD of $1.74 \mathrm{kPa}$ was recorded in August 2016.

Daily average and 7-day moving average of GPP and $R_{\mathrm{e}}$ are presented in Figure $3 a$ and $b$. During the whole period of study annual GPP of the forest was $2660.07 \mathrm{~g} \mathrm{C} \mathrm{m}^{-2}$ year $^{-1}$. Estimated GPP in this study is close to the model estimated GPP of $2.11 \mathrm{~kg} \mathrm{C} \mathrm{m}^{-2}$ year $^{-1}$ in the same ecosystem from July 2015 to June 2016 (ref. 11). Daily average of GPP showed a peak of $15.86 \mathrm{~g} \mathrm{C}$ $\mathrm{m}^{-2}$ day $^{-1}$ in the last part of April, whereas a minimum GPP of $1.58 \mathrm{~g} \mathrm{C} \mathrm{m}^{-2}$ day $^{-1}$ was recorded in January 2017 (Figure $3 a$ ). Most of the high values of GPP were observed from May to June 2016 which is attributed to the occurrence of favourable conditions for photosynthesis in the forest with high values of PAR coupled with high LAI. Reduction of daily average GPP to $1.58 \mathrm{~g} \mathrm{C} \mathrm{m}^{-2}$ day $^{-1}$ in January signifies leafless condition of the forest canopy which was caused by leaf senescence and abscission along with dry soil conditions. Estimated GPP was low in July due to low radiation received by the site and is in agreement with Thomas et al. ${ }^{18}$. GPP values were 

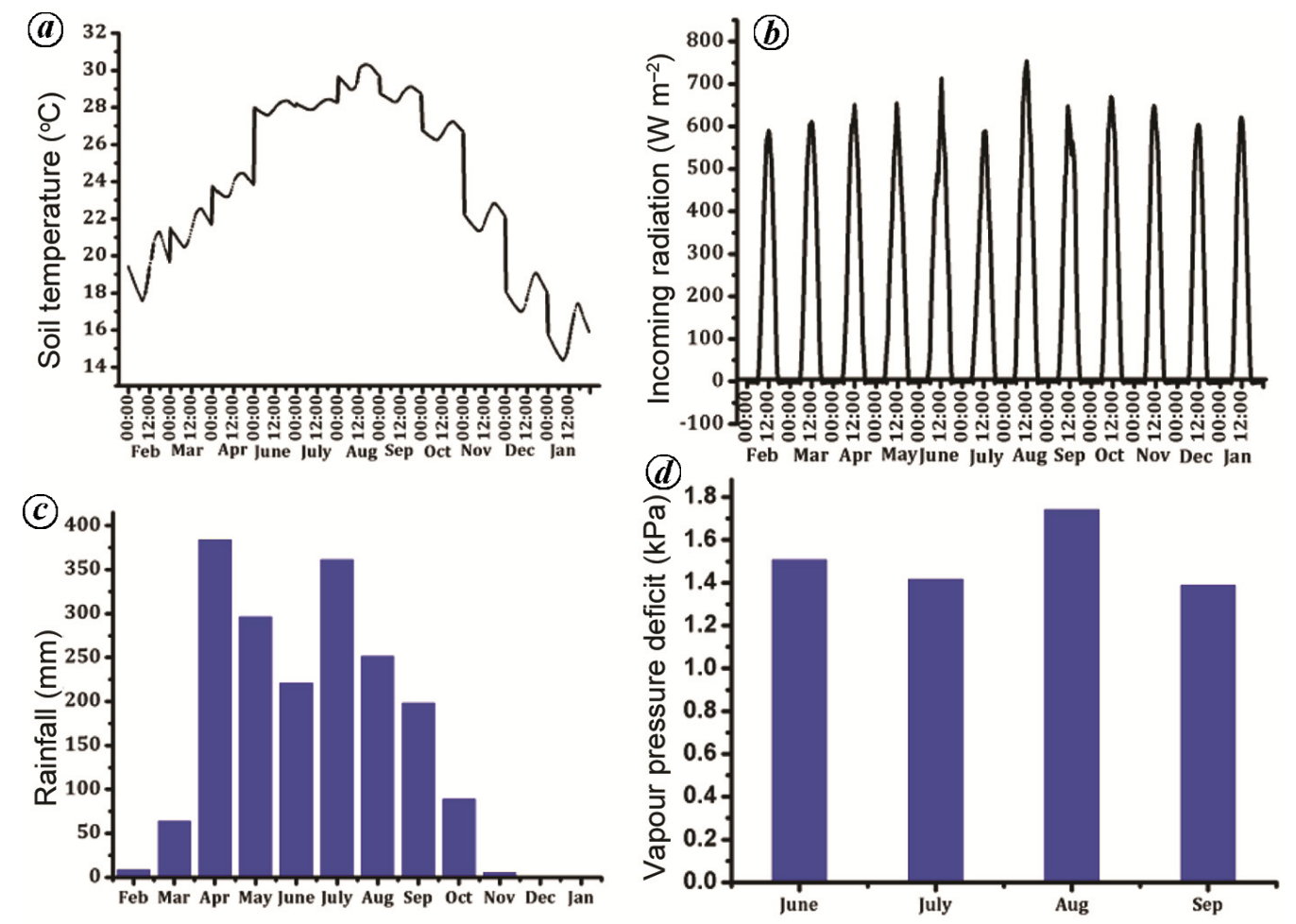

Figure 2. $\boldsymbol{a}$, Diurnal variations (monthly mean) of soil temperature; $\boldsymbol{b}$, Diurnal variations (monthly mean) of incoming solar radiation; $\boldsymbol{c}$, Monthly total rainfall recorded in the site; $\boldsymbol{d}$, Day-time average of VPD during monsoon season.
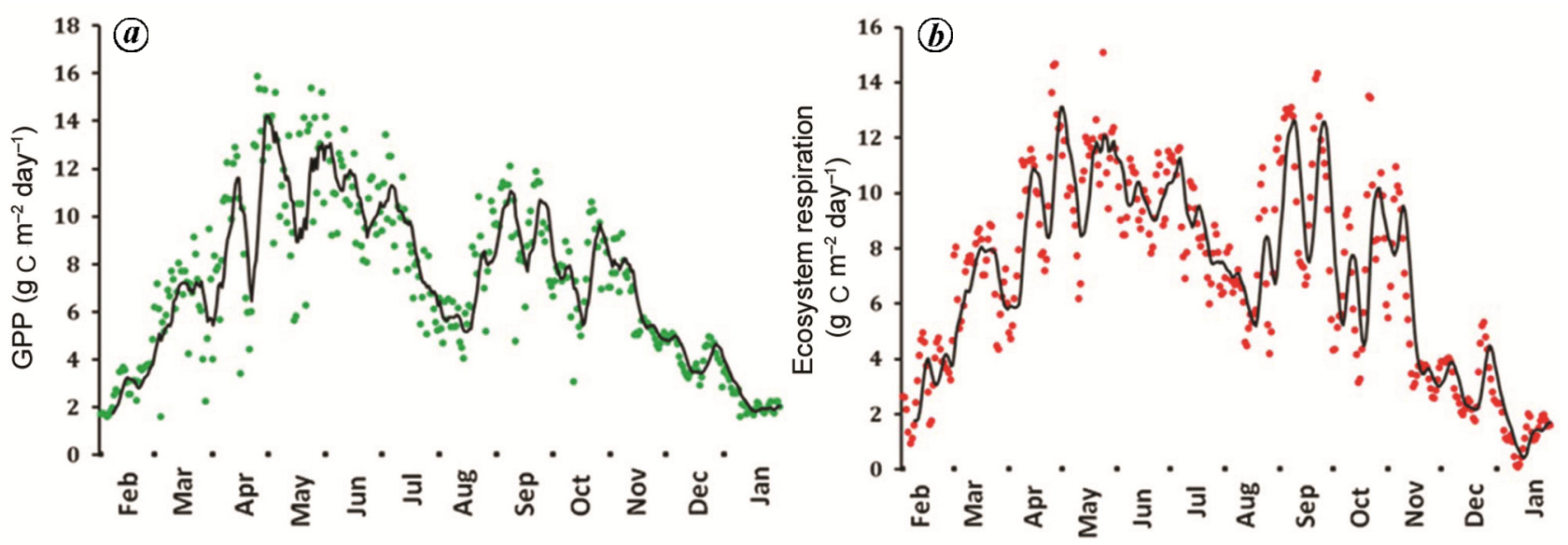

Figure 3. Daily averages of (a) GPP and (b) ecosystem respiration; daily averages in the figures are indicated by dots and bold line indicates 7 days moving average.

also low during August which was caused by partial stomatal closure of forest canopy as a result of high VPD in August. Similar relationship between VPD and stomatal closure was also reported by Pita et $a l .{ }^{4}$ in their study over four forest sites of Belgium and France. Decrease of GPP in the mid monsoon period is also attributed to the limitation of photosynthetic activity of understorey vegetation owing to waterlogged condition of the site.

Daily and weekly averages of ecosystem respiration are plotted in Figure $3 \mathrm{~b}$. Over the annual cycle of study the estimated $R_{\mathrm{e}}$ was $2567.13 \mathrm{~g} \mathrm{C} \mathrm{m}^{-2}$ year $^{-1}$. Daily average respiration of this semi-evergreen forest ranged between $0.06 \mathrm{~g} \mathrm{C} \mathrm{m}^{-2} \mathrm{day}^{-1}$ and $15.06 \mathrm{~g} \mathrm{C} \mathrm{m}^{-2} \mathrm{day}^{-1} . R_{e}$ increased continuously from February to May 2016 due to increase in temperature and soil moisture ${ }^{16}$; similar findings were also reported by Heinemeyer et al. ${ }^{19}$. During this period a significant change in matric potential of soil can make heterotrophic microbiota more active ${ }^{20}$. Remarkable decrement in ecosystem respiration was observed from the beginning of the monsoon season (June) to August 2016 which was perhaps caused by water stagnation in the site, resulting in decreased 

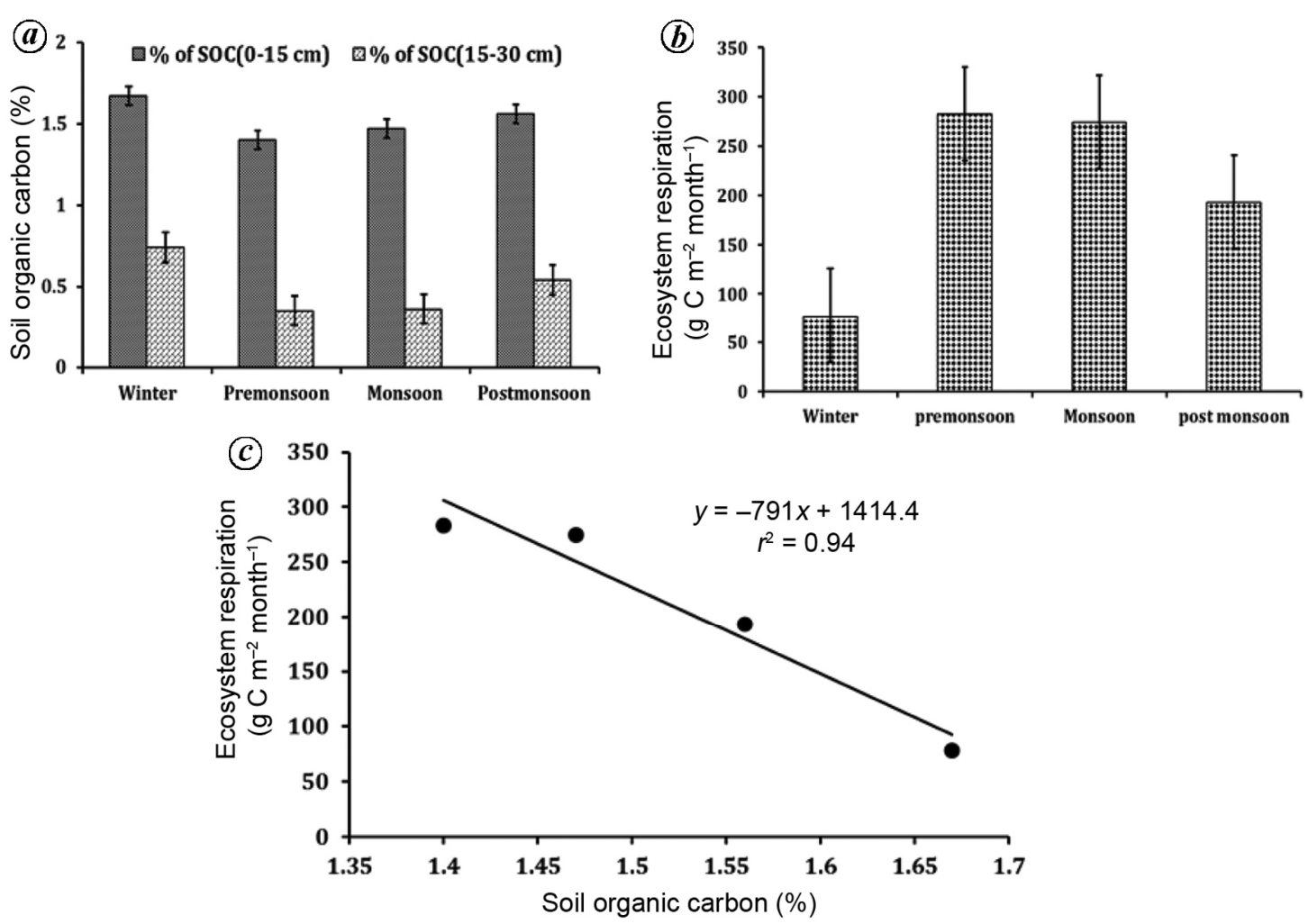

Figure 4. $\boldsymbol{a}$, Variation of SOC (average) in four seasons; $\boldsymbol{b}$, Seasonal average of ecosystem respiration; $\boldsymbol{c}$, Negative correlation between seasonal average of SOC and seasonal average of ecosystem respiration.
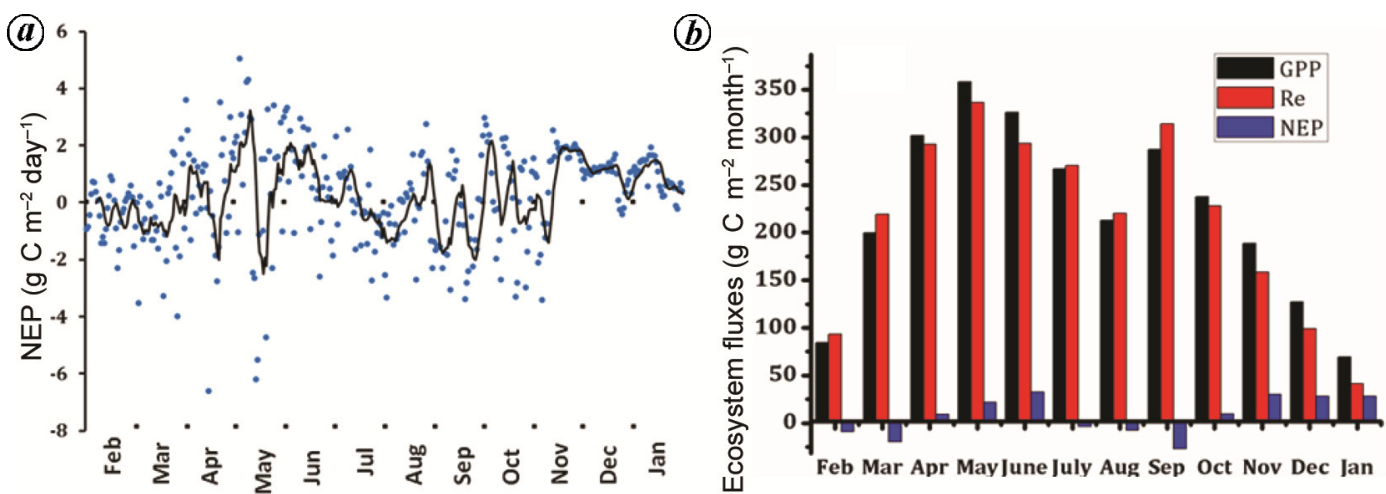

Figure 5. $\boldsymbol{a}$, Daily averages of NEP, daily averages in the figure are indicated by dots and the bold line indicates 7 days moving average; $\boldsymbol{b}$, Monthly total of GPP, ecosystem respiration and NEP.

respiration rates from the soil (autotrophic and heterotrophic) and other herbaceous plants accompanied by reduced root respiration. Similar observation of reduction of $\mathrm{CO}_{2}$ efflux from soil during the wet period was reported $^{21}$ from an oak plantation ecosystem in northeastern Himalayan region. Ecosystem respiration started to increase from September as a result of withdrawal of stagnated water and due to decomposition of leaf litter in soill $^{18}$ as evident from the decrease in LAI in September ${ }^{10}$. With the progress of the dry season (October 2016 to January 2017), respiration of the ecosystem decreased slowly and became almost negligible in January as a result of low soil temperature. Results of SOC in both the depths during four seasons are presented in Figure $4 a$. SOC content was highest in winter season and lowest in pre-monsoon season. Average ecosystem respirations for each season is presented in Figure $4 b$. The regression analysis between seasonal average of ecosystem respiration and seasonal average of SOC (Figure $4 c$ ) showed negative correlation (adj $r^{2}=0.92, P<0.05$ ). Highest SOC content in soil during the winter season might have been caused by high litter fall and low respiratory loss of $\mathrm{CO}_{2}$ from soil due to dry and cold condition. The estimated SOC values were slightly lower during pre-monsoon 


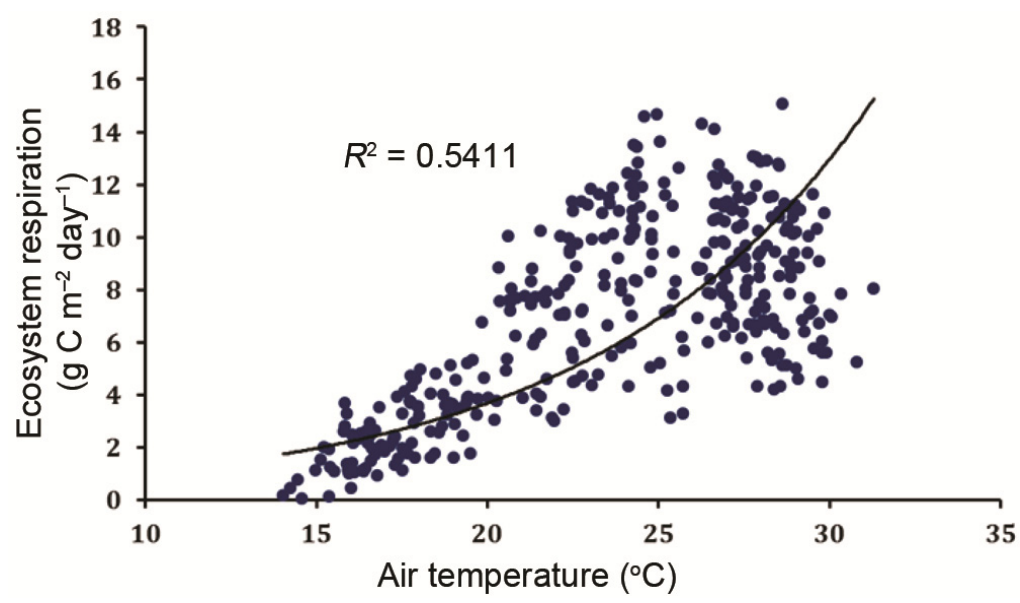

Figure 6. Relationship between temperature of air and ecosystem respiration during the study period $(P<0.01)$.
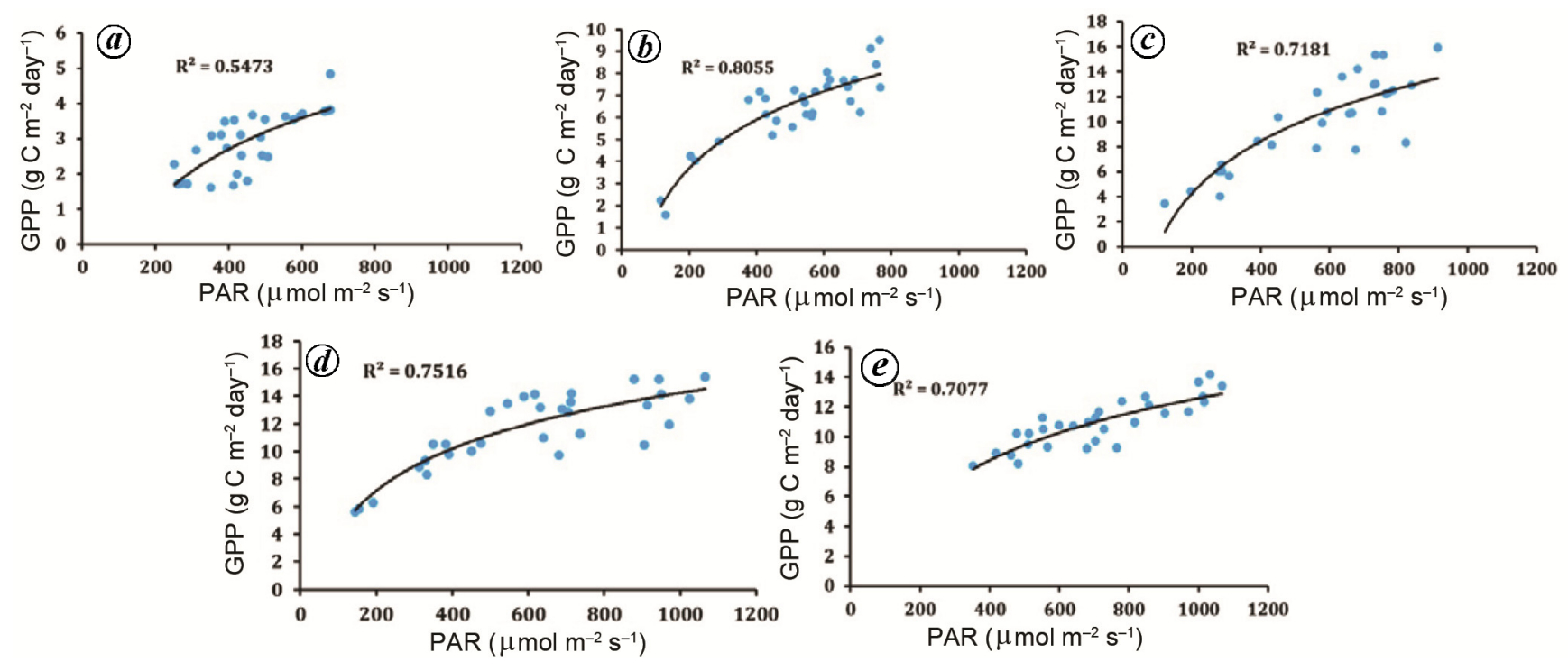

Figure 7. PAR versus GPP in different months: $\boldsymbol{a}$, February; $\boldsymbol{b}$, March; $\boldsymbol{c}$, April; $\boldsymbol{d}$, May; $\boldsymbol{e}$, June, $P<0.001$ (in all the cases).

season due to high soil respiration as a result of increased microbial activity (Figure $4 a$ ). Similar seasonal variation of SOC was reported by Sheikh et al. ${ }^{22}$ in their study on SOC variation over different forest ecosystems in Garhwal Himalaya, India. The estimated annual ecosystem respiration of KNP is higher compared to the reports from other sites ${ }^{6}$ owing to the complex structure of northeastern forest ecosystem and unique climatic conditions ${ }^{9}$.

Although high fluctuation in daily average NEP was observed (Figure 5a), the weekly mean followed a distinct pattern. Daily average NEP showed a peak of $5.03 \mathrm{~g} \mathrm{C} \mathrm{m}^{-2}$ day $^{-1}$ at the beginning of May. In Figure $5 a$, positive and negative values of NEP represent net uptake and release of carbon respectively. Estimated annual NEP of $92.93 \pm 1.7 \mathrm{~g} \mathrm{C} \mathrm{m}^{-2}$ year $^{-1}$ indicates that $\mathrm{KNP}$ is a small sink of carbon. The annual NEP of KNP is lower compared to other similar ecosystems which might be because of higher ecosystem respiration and lower LAI of the forest ${ }^{6}$.

Monthly sums of GPP, ecosystem respiration and NEP are shown in Figure $5 b$, the highest monthly total of GPP and ecosystem respiration was observed in May 2016 just before the arrival of Indian summer monsoon in the region. In February and March the forest acted as net carbon source. Monthly total GPP dominated the respiration from April to June causing the ecosystem to act as a carbon sink. From the middle to end of monsoon season (July-September), the ecosystem released carbon (source) to the atmosphere as a result of dominance of $R_{\mathrm{e}}$ over GPP, a similar role of $R_{\mathrm{e}}$ in controlling the variation of NEP was also reported from European forests ${ }^{6}$. From October to January the ecosystem acted as a sink of carbon.

We have made an attempt to find a co-relationship between air temperature and ecosystem respiration 
(Figure 6) during the whole study period and observed a fairly good correlation $r^{2}=0.54(P<0.01)$ between the two parameters. Impact of PAR on GPP was analysed month-wise and the results are presented in Figure $7 a-e$. Good correlation between PAR and GPP was observed from March to June $(P<0.001)$. From July to January the correlation between PAR and GPP remained insignificant.

\section{Conclusion}

Remarkable seasonal variation of ecosystem respiration has been observed in this study which has a significant role over annual NEP of KNP. Stagnated water during monsoon showed significant influence over the monthly variation of ecosystem respiration during that period. The forest ecosystem of KNP acted as a moderate carbon sink with annual NEP of $92.93 \mathrm{~g} \mathrm{C} \mathrm{m}^{-2}$ year $^{-1}$. Estimated annual GPP and ecosystem respiration of the forest are $2660.07 \mathrm{~g} \mathrm{C} \mathrm{m}^{-2}$ year $^{-1}$ and $2567.13 \mathrm{~g} \mathrm{C} \mathrm{m}^{-2}$ year $^{-1}$ respectively. Monthly variation of NEP indicated the highest carbon fixation potential of KNP forest in June.

1. Bhattacharyya, P., Neogi, S., Roy, K. S. and Rao, K. S., Gross primary production, ecosystem respiration and net ecosystem exchange in Asian rice paddy: an eddy covariance-based approach. Curr. Sci., 2013, 104(1), 67-75.

2. Magnani, F. et al., The human footprint in the carbon cycle of temperate and boreal forests. Nature, 2007, 447, 848-850.

3. Beer, C. et al., Terrestrial gross carbon dioxide uptake: Global distribution and covariation with climate. Science, 2010, 329, 834838 .

4. Pita, G., Gielen, B., Zona, D., Rodrigues, A., Rambal, S., Janssens, I. A. and Ceulemans, R., Carbon and water vapor fluxes over four forests in two contrasting climatic zones. Agric. For. Meteorol., 2013, 180, 211-224.

5. Carrara, A., Janssens, I. A., Yuste, J. C. and Ceulemans, R., Seasonal changes in photosynthesis, respiration and NEE of a mixed temperate forest. Agric. For. Meteorol., 2004, 126, 15-31.

6. Valentini, R. et al., Respiration as the main determinant of carbon balance in European forests. Nature, 2000, 404, 861-865.

7. Giardina, C. P. and Ryan, M. G., Evidence that decomposition rates of organic carbon in mineral soil do not vary with temperature. Nature, 2000, 404, 858-861.

8. Krishna, M. P. and Mohan, M., Litter decomposition in forest ecosystems: a review. Energ. Ecol. Environ., 2017, 2, 236-249.

9. Mahanta, R., Sarma, D. and Choudhury, A., Heavy rainfall occurrences in northeast India. Int. J. Climatol., 2013, 33, 1456-1469.

10. Sarma, D., Baruah, K. K., Baruah, R., Gogoi, N., Bora, A., Chakraborty, S. and Karipot, A., Carbon dioxide, water vapour and energy fluxes over a semi-evergreen forest in Assam, Northeast India. J. Earth Syst. Sci., 2018, 127(7).

11. Deb Burman, P. K., Sarma, D., Williams, M., Karipot, A. and Chakraborty, S., Estimating gross primary productivity of a tropical forest ecosystem over north-east India using LAI and meteorological variables. J. Earth Syst. Sci., 2017, 126.

12. Rodda, S. R., Thumaty, K. C., Jha, C. S. and Dadhwal, V. K., Seasonal variations of carbondioxide, water vapor and energy fluxes in tropical Indian mangroves. Forests, 2016, 7(35).

13. Lasslop, G. et al., Separation of net ecosystem exchange into assimilation and respiration using a light response curve approach: critical issues and global evaluation. Global Change Biol., 2010, 16, 187-208.

14. Falge, E. et al., Gap filling strategies for defensible annual sums of net ecosystem exchange. Agric. For. Meteorol., 2001, 107, 43-69.

15. Lloyd, J. and Taylor, J. A., On the temperature dependence of soil respiration. Funct. Ecol., 1994, 8(3), 315-323.

16. Reichstein, M. et al., On the separation of net ecosystem exchange into assimilation and ecosystem respiration: review and improved algorithm. Global Change Biol., 2005, 11, 1424-1439.

17. Korner, C., Leaf diffusive conductances in the major vegetation types of the globe. In Ecophysiology of Photosynthesis (eds Schulze, E. D. and Caldwell, M. M.), Springer, Berlin, 1995, pp. 463-490.

18. Thomas, M. V. et al., Carbondioxide fluxes over an ancient broadleaved deciduous woodland in southern England. Biogeosciences, 2011, 8, 1595-1613.

19. Heinemeyer, A., Hartley, I. P., Evans, S. P., Fuente, J. A. and Ineson, P., Forest soil $\mathrm{CO}_{2}$ flux: uncovering the contribution and environmental responses of ectomycorrhizas. Global Change Biol., 2007, 13, 1786-1797.

20. Veenendaal, E., Kolle, O. and Lloyd, J., Seasonal variation in energy fluxes and carbondioxide exchange for a broad-leaved semi-arid savanna (Mopane woodland) in Southern Africa. Global Change Biol., 2004, 10, 318-328.

21. Pandey, R. R., Sharma, G., Singh, T. B. and Tripathi, S. K., Factors influencing soil $\mathrm{CO}_{2}$ efflux in a northeastern Indian oak forest and plantation. Afr. J. Plant Sci., 2010, 4, 280-289.

22. Sheikh, M. A., Kumar, M. and Bussmann, R. W., Altitudinal variation in soil organic carbon stock in coniferous subtropical and broadleaf temperate forests in Garhwal Himalaya. Carbon Balance Manage., 2009, 4(6).

ACKNOWLEDGEMENTS. We acknowledge the forest department, Govt of Assam and the forest ranger of Burhapahar Range for providing logistic support in carrying this study. We acknowledge $\mathrm{Mr}$ Jintu Sarma for his help in identifying the plant species of the study area. We are grateful to IITM, Pune for providing financial support during the period of this study.

Received 12 April 2018; revised 22 November 2018

doi: $10.18520 / \mathrm{cs} / \mathrm{v} 116 / \mathrm{i} 5 / 751-757$ 